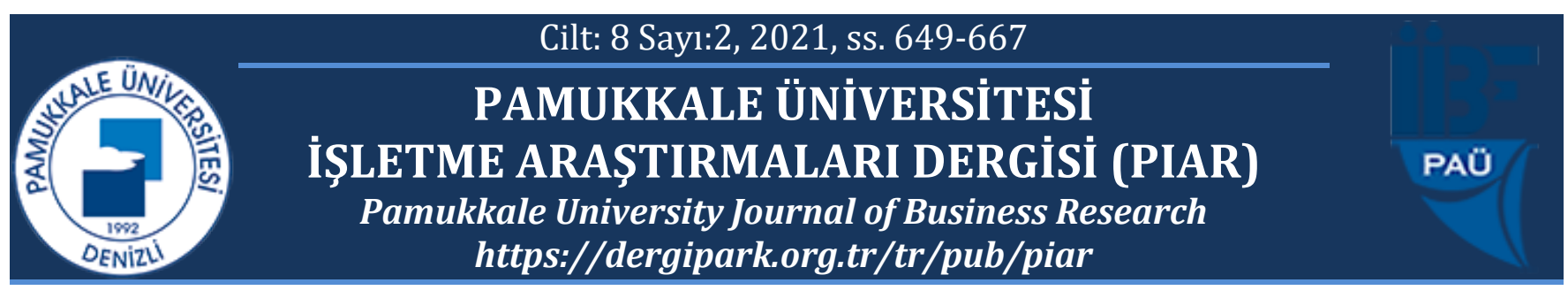

\title{
Bir Servis Robotu Olarak Telepresence (Uzabulunum) Robotlar
}

\author{
Telepresence Robots As A Service Robot
}

\begin{abstract}
Ahmet İlker AKBABA ${ }^{*}$ *
${ }^{1}$ Erzurum Teknik Üniversitesi, İ̈BF, İşletme Bölümü, aakbaba@erzurum.edu.tr, https://orcid.org/0000-0003-3256-441X 2 Erzurum Teknik Üniversitesi, SBE, İşletme ABD, cagla.gundogdu49@erzurum.edu.tr, https://orcid.org/0000-00031903-7113

* Yazışılan Yazar/Corresponding author

\section{Çağla GÜNDOĞDU²}

Makale Geliş/Received: 20.11.2021

\begin{abstract}
Öz
Yirmi birinci yüz yılın sanayi devrimi olan Endüstri 4.0, makineleşme ve dijitalleşme sürecinde tüm bileşenleriyle insan unsurunun en aza indirgenerek üretim süreçlerinde maksimum verimin sağlanması prensibine dayanan bir yaklaşımdır. Dijital çağa uyum sağlayabilmek adına birçok bileşeninin ayı anda ya da farklı farkl zaman dilimlerinde üretim süreçlerine uyarlanarak maliyet optimizasyonunun sağlanması hedeflenmiştir. Endüstri 4.0 kapsamında üretim süreçlerine birden fazla donanım ve ileri düzeyde yazılımlarla donatılmış, yapay zekâ tabanıyla insan davranışlarını taklit edebilme, hareket başlatabilme kabiliyetlerine sahip ve bilgisayarlar aracılığılyla kontrol edilebilen robot sistemleri dahil edilmiştir. Kullanuclları zaman ve mekân kısıtından uzaklaştırarak, bir tablet ya da bilgisayar ekranı ve standı ile uzaktan kontrole imkân veren, farkl bir konumda olabilme ve bu konum içerisinde faaliyet gösterimine imkân veren telepresence robotlar ise bu elektromekanik sistemin bir alt başlı̆̆ 1 olarak kullanılmaya başlanmıştır. Sağlık, konaklama, inşaat, tarm sektörlerine yönelik profesyonel robotlar geliştirilip, üretilip-satılmaktadır. Telepresence robotlar da sunduğu imkanlarla çeşitli alanlarda kullanılmaya başlanmıştır. Bu çalışmada da çok yeni bir kavram olan ve literatürde çok az değinilen telepresence robotlarm tanımına, çalışma prensibine ve genel olarak kullanım alanlarına değinilmiştir.
\end{abstract}

Anahtar kelimeler: Uzabulunum, telepresence, robot, hizmet, endüstri 4.0

JEL kodları: M11, M15, O32
Makale Kabul/Accepted: 22.12.2021

Makale Kabul/Accepted: 22.122021

\begin{abstract}
Industry 4.0, which is the industrial revolution of the twenty-first century, is an approach based on the principle of minimizing the human factor with all its components in the mechanization and digitalization process and ensuring maximum efficiency in production processes. In order to adapt to the digital age, it is aimed to achieve cost optimization by adapting many components to the production processes at the same time or in different time periods. Within the scope of Industry 4.0, robot systems equipped with multiple hardware and advanced software, capable of imitating human behavior with artificial intelligence, initiating movement and controlled by computers, were included in the production processes. Telepresence robots, which allow remote control with a tablet or computer screen and stand, taking users away from time and space constraints, allowing to be in a different location and displaying activities in this location, have started to be used as a sub-title of this electromechanical system. Professional robots for health, accommodation, construction and agriculture sectors are developed, produced and sold. Telepresence robots have also started to be used in various fields with the opportunities they offer. In this study, the definition, working principle and general usage areas of telepresence robots, which is a very new concept and rarely mentioned in the literature, are mentioned.
\end{abstract}

Keywords: Telepresence, robot, service, industry 4.0 


\section{GİRİş}

Dünya tarihi boyunca her devrin bilim, felsefe ve teknik gelişmişlik düzeyleri yine ilgili toplumların yaşam biçimlerinin yanında üretim süreçlerini de etkilemiştir. 18. yüzyılda başlayan sanayileşme süreci kadim medeniyetlerin kat ettiği gelişme düzeyini hızlandıran karakterize bir çarpan olarak yerini almış ve her geçen süreçte biraz daha gelişmiş olan evreleriyle toplumları etkilemeye devam etmiştir. İçerisinde bulunduğumuz 21. yüzyılda toplum ve iktisadi otoritelerin bilgi birikimlerinin ilerleyen teknoloji araçları ile hızla ulaşılabilir hale gelmesi, kolayca iletilebilmesi ve tüm süreçlere yön vermesiyle yaşadığımız çağın yapısında köklü değişiklikler meydana getirmiş ve Endüstri 4.0 kavramını ortaya çıkarmıştır. Sanayi devrimlerinin dördüncü düzeyi olan Endüstri 4.0 yapay zekâ, $3 \mathrm{~d}$ yazıcılar, nesnelerin interneti, bulut bilişim, büyük veri ve robotik sistemleri içeren bir değerler bütünü olarak görülebilir.

Sanayileşme süreçleri önceki dönemlerde klasik anlamıyla makineleşme kavramı etrafında şekillenirken Endüstri 4.0 basamağını bu kavramla sınırlamak doğru olmayacaktır. Üreticiler bu evrede dijitalleşen uygulamalar ya da platformlarla beraber iş yapma biçimlerini geliştirerek farklı bileşenlerden yararlanmışlardır. Bu etmenlerden birisi de robotik sistemlerdir.

Üreticilerde olduğu kadar toplumlarda da dijital çağa uyum süreci gelişmiş ve tüm sektörlerden beklentiler yine çağa uygunluk olmuştur. Eğitim, sağlık ve eğlence gibi sektörlerde de üreticilerin farklı kanallardan, müşteri odaklı ve kaliteli hizmet deneyimine yönelik adımlarının önemi artmıştır. Toplumların bu süreçte her alanda aynı ivmeyi beklemeleri Endüstri 4.0 bileşenlerinin hemen hemen her alanda kullanılmasına zemin oluşturmuştur. Son yıllarda sektörlerde robotlaşma kavramı birçok açıdan ele alınmıştır. Rekabet açısından her çağa uyumlanması gereken sektörler henüz çok yeni bir kavram olmasına rağmen telepresence robot sistemleri ile ilişkilendirilmeye başlanmıştır. Böylece günümüzde insan ve sistem entegrasyonu sağlanarak hem verimlilik artışı hem de çağa uygunluk gözetilmiştir.

\section{ENDÜSTRI 4.0 VE ROBOTIK SİSTEMLER}

Teknolojinin katlanarak ilerlemesiyle sanayileşme süreçleri hızlanmış ve 21. yüzyılda 4. evre olan Endüstri 4.0 dönemi başlamıştır. İlk olarak Almanya'da 2011 yılına düzenlenen Hannover Konferansı ile kavramsallaştırılmıştır. Dördüncü sanayi devrimi; yapay zekâ, nesnelerin interneti ve robotik sistemler gibi birden çok teknolojik unsuru içerisinde bulunduran ve insan gücünün en alt seviyede kullanımıyla teknolojiden maksimum ölçüde yararlanarak verimlilik, maliyet, zaman gibi kavramlarda optimalliğin sağlanmasına yönelik çalışmaların sürdürüldüğü bir sistem bütünü olarak açıklanabilir (Bahrin vd., 2016: 139-140).

Dördüncü sanayi devrimi tüm iş birlikçileriyle bir dijitalleşme süreci olarak düşünülebilir. Endüstri 4.0'ın kapsadığı bileşenler ürün ya da hizmet üretimlerinde çoğu zaman birlikte kullanılmış ve bu bileşenler güçlü ya da kısıtlayıcı yönleri göz önüne alınarak entegre edilmiş böylece üretim süreçlerine daha verimli bir şekilde dahil edilmiştir (Goel ve Gupta, 2020).

Mevcut sanayi devrimi ile üretim süreçlerine dahil edilen bir sistem bütünü olan robotlar ilk kullanım süreçlerinde iş güvenliği gerektiren ve tam olarak otomatikleşme gerektiren iş 
kollarını kapsarken değişen koşullarla beraber birden fazla alana ve kullanım biçime uyum sağlamıştır (Gao vd. 2020: 598).

Dijitalleşme süreci ile pazar kavramı değişmiş ve global ölçüde hizmet veren firma sayısı giderek artmıştır. Sanal ekipleşme süreçlerinde insan gücü ve robotik sistemlerin iş birliği giderek yaygınlaşmış; insan ve robotların doğrudan iş birliğini içeren kolaboratif robotların kullanımı, insan ve robotların farklı zaman dilimlerinde kullanıldı̆̆ı hibrit bir çalışma düzeniyle ya da tamamen robotlaşan bir çalışma biçimi ile hem hizmet hem de ürün üretimlerinde yer edinmişlerdir (Richert, 2016: 142).

Bu kapsamda tanımlanan iş yüklerine göre robotlar iki başlık altında incelenebilir: İlki endüstriyel üretimlerde kullanılan ve en az 3 mekanik temelden oluşan sabit ya da hareketli olabilen otomatik veya kontrol edilebilen manipülatörler olarak bilinen endüstriyel robotlardir (Topkaya, 2016: 1131).

Endüstriyel robotlar firmaların iş entegrasyonu ile verimlilik, zaman ve maliyet optimizasyonunda insan kaynaklı aksamaları minimize etmek adına yöneldikleri bir opsiyondur. Gelişen teknolojilerle beraber fonksiyonları artan endüstriyel robotlar özellikle ürün üretimlerinde üreticiler için büyük bir teknolojik gelişme olmuştur (Çengelci ve Çimen, 2005: 70).

İkincisi ise otonom ya da kısmi otonom sistemlere sahip, günlük hayatı kolaylaştırmaya yönelik ev içi kullanıma yönelik üretilenlerin yanı sıra eğitim, sağlık, turizm gibi faaliyetlerde görev yüklenilen servis robotları olarak tanımlanabilir (Severinson-Eklundh, 2003: 226).

Servis robotları özellikle eğitim, sağlık, silahlı kuvvetler, lojistik gibi alanlarda kullanılmış ve endüstriyel robotlardan türetilmiş bir sistemler bütünü olarak görülebilir. Ürün üretiminden ziyade hizmet üretiminde kullanımlarıyla günlük hayatı kolaylaştırma yönüyle endüstriyel robotlardan ayrılarak insan-robot iş birliğinde atılan adımları ilerletmiştir (Furat ve Fırat, 2017: 67).

2000 yılında 1 milyon civarında olan endüstriyel robot sayısı 2010 yılında 9 milyona yaklaşmıştır ve birkaç on yıl içerisinde robotların sayısının dünya nüfusunu geçeceği öngörülmektedir. Bu sebeple robot teknolojileri, Endüstri 4.0'ın etkisini artırmak açısından gelecek vadetmektedir (Akbaba, 2019: 11). Uluslararası Robotik Federasyonu (IFR) tarafından yayınlanan 2020 raporuna göre son 5 yılda robot kullanımlarındaki artış \%85 oranıyla en yüksek noktaya ulaşarak toplamda 376 bin üniteye erişmiştir. Yine aynı veriler kontrol edildiğinde 2,7 milyon endüstriyel robot kullanılmış bu sayıyla toplamda \%12 oranlı bir artış seyri göstermiştir. İşbirlikçi robotlar olarak cobotlar 129,600 sayısına ulaşarak \%11 oranlı bir büyüme seyri göstermiş ve bu oran endüstriyel robotların \%4,8'i olarak belirlenmiştir. Bu verileri göz önüne aldığımızda genel anlamda robotların öncelikle endüstri sonrasında da hizmet sektörlerinde kullanımının arttığı ve ileriye yönelik artış göstereceği gözlenmiştir (https://ifr.org/worldrobotics/).

\section{LITERATÜR ARAŞTIRMASI}

Teknolojik gelişmelerle birlikte telepresence uygulamalar ile ilgili araştırmalar literatürde yer almaya başlamıştır. Bu uygulamalar uzak bölgelerdeki insanlar arasındaki etkileşim konularının ele alınmasına önemli katkılar sağlamış ve uzaktan iletişim ile ilgili 
uygulamaların multimedya konferans, tele-tıp ve tele-eğitim gibi birçok farklı alanda kullanılması hedeflenmiştir (Walker ve Sheppard, 1997).

Telepresence uygulamalarının kullanıldığı alanlara yönelik sınırlı sayıda yerli çalışma olması nedeniyle özellikle yabancı literatürde yer alan çalışmalar aşağıda verilmiştir.

Kwon ve diğerleri (2010) çalışmalarında telepresence robotları ele almış ve anadili İngilizce olan öğretmenlerin uzaktan robot kontrolü yardımıyla İngilizce eğitimi vermesinin öğrenciler üzerindeki etkisini incelenmiştir. Bu robotlar sayesinde anadili dişında farklı bir dil öğrenmek isteyen öğrencilere teknolojik imkanlar ile kolaylık sağlanması hedeflenmiştir.

Tanaka ve diğerleri (2013) çalışmalarında farklı ülkelerde yer alan okullar arasında telepresence robotlarla birlikte bir bağlantı kurulmasının eğitime olan katkısı incelenmiş ve pilot bölge olarak seçilen Japonya ve Avustralya sınıfları arasında uluslararası bir derleme yapılmıştır. İki farklı ülkede yer alan sınıfların birbirleriyle entegre olması ve eğitim farklılıklarının öğrenciler üzerinde etkileri sunulmuştur.

Gonzalez Jimenez ve diğerleri (2013) çalışmalarında İspanya'da yaşlılar için kullanılması planlanan telepresence robotlara yönelik bir araştırma sunuldu. Giraff telepresence robotların üç farklı test alanında kullanımı bir yıldan fazla bir süre için incelendi ve bu değerlendirmeden elde edilen bulgular, yaşlıların yaşam standartlarının iyileştirilmesine yönelik bu teknolojinin gelecekteki gelişmeleri için temel oluşturduğu gözlemlendi.

Bevilacqua ve diğerleri (2014) çalışmalarında halen devam etmekte olan ve bir yıla aşkın bir süredir kullanılan telepresence robotların günlük yaşamda parkinson hastası olan yaşlı bireyler ve bu bireylerin aileleri üzerine inceleme gerçekleştirildi. Çalışma ile uzakta olan aile bireylerinin parkinson hastası yaşlılar ile kolayca iletişimde bulunmaları ve hasta olan kullanıcının yardıma karşı tutumu ve zaman içinde sürekli olarak olumlu bir tutum sergilemesinin sabit olması tespit edilmiştir.

Çavdar ve diğgerleri (2016) çalışmalarında uzaktan kontrol edilebilen, eşzamanlı karşılıklı ses ve görüntü transferi sağlayan, engel algılayan, kullanım kolaylığı sağlayan arayüzlere ve beyaz tahta uygulamasına sahip, uygun maliyetli bir uzabulunum robot tasarlamışlardır.

Okamura ve diğerleri (2016) çalışmalarında iki yönlü çalışabilen telepresence robotları ele alınmıştır. Yaşlıların ihtiyaç duydukları iş desteği sağlamak ve bu kişilerin ilkokul öğrencilerine uzaktan eğitim vermelerine olanak sunmak için telepresence robotlardan nasıl yararlanıldığını incelenmiştir. Bu robotlar sayesinde hem yaşlı insanların iş hayatında aktif olarak yer alması hem de öğrencilerin bu kişilerin tecrübelerinden yararlanılması hedeflenmiştir.

Cha ve diğerleri (2017) çalışmalarında telepresence robotların farklı nedenlerle okula gidemeyen ve uzaktan eğitim görmekte olan öğrencilerin sinıflara entegre olması üzerine eğitimdeki etkileri incelenmiştir. Telepresence robotların eğitim sektörü üzerinde etkisi ele alınmış ve bu sistemlerde kullanılmasının avantaj ve dezavantajları sunulmuştur.

Yang ve diğerleri (2018) çalışmalarında telepresence robotların birçok farklı nedenden kaynaklı olarak alışveriş yapamayan kişilerin alışveriş imkânı bulması konusu üzerine çalışma gerçekleştirildi. Çalışmalarında uzaktan kontrol ettikleri telepresence robot ile 
kişilerin temel ihtiyaçlarını kolayca halledebilmeleri ve bu sayede insanların diğer kişilere olan bağımlılıklarının azalması gözlemlendi.

Yang ve diğerleri (2018) çalışmalarında telepresence robotların uzak mesafe ilişkisine sahip eşlerin üzerindeki etkileri incelendi ve telepresence robot eşler arasındaki iletişime etki ettiği alanlar tespit edildi. Uzak mesafe ilişkisinde eşler arasında beş farklı alanda etkileşimleri telepresence robotlar sayesinde kolaylaştırıldığı tespit edildi: eşlerin sıradan günlük rutinlere katılımı, bu kişilerin bir evi paylaşma duyguları, kişinin eşinin ailesi ve arkadaşlarıyla bağlantı kurma kolaylığı, artan yardımseverlik ve sessiz arkadaşlıktan keyif alma gibi farklı birçok özellik bu robotlar sayesinde incelendi.

Carranza diğerleri (2018) çalışmalarında Filipinler'de sıkça karşılaşılan hastaların yeteri kadar doktora ulaşama problemi üzerine telepresence robotlar ile bu sorunun çözümüne yönelik bir araştırma gerçekleştirildi. Çalışma sonucunda ölüm riskinin büyük bir oranını oluşturan hastalara yönelik yetersiz doktor gözlemi sorunun teleprence robotlar sayesinde azaldığı gözlemlendi.

Brett ve diğerleri (2018) çalışmalarında telepresence robotların iş hayatında yer alan ekip çalışmaları incelendi. İnceleme gerçekleştirilirken ekip üyelerinin uzaktan erişim ile bir bulmacayı çözmesi istendi ve sonuçlar değerlendirildi. $\mathrm{Bu}$ robotlar sayesinde uzakta bulunan ekip üyelerinin ekip içerisine entegre edilmesinin kolaylaştığı, iletişimin haberleşme cihazlarına göre daha verimli olduğu gözlemlendi.

Cortellessa ve diğerleri (2018) çalışmalarında Robin adında gelişmiş bir telepresence robotun evde olan yaşlı yetişkinleri desteklemek ve onları gözlemlemek için kullanılmasını incelendi. Robin adında olan bu robot evlerinde yalnız yaşayan veya bir bakıcı gözetiminde bulunan yaşlıların fiziksel ve psikolojik sağlık durumlarını sürekli olarak izlemenin kolaylaşması ve sensör açısından zengin bir ortama alışılması sağlandığı tespit edildi. Ayrıca yaşlı bireylerin bakıcıları veya yardım aldıkları kişilerle daha iyi bir iletişim kurmasına yardımcı oluğu da tespit edildi.

Fischer ve diğerleri (2019) çalışmalarında okullarda rehberlik ve psikolojik danışmanlık hizmetine ihtiyaç duyan fakat eğitim imkanları sınırlı olan okul öğrencileri için okul psikolojik danışmanlarının uzaktan danışmanlık yapmasına olanak sağlanması için telepresence robotların önemi incelenmiştir. Telepresence robotların klasik uzaktan video konferans yapilarından farkları sunulmuştur.

Tan ve diğerleri (2019) çalışmalarında okul sistemleri için geliştirilmiş olan telepresence robotlarla desteklenen laboratuvarlar incelenmiştir. Laboratuvar derslerinin uzaktan eğitimde hem öğrenci hem de dersi verecek olan öğretim görevlileri için sorunlara neden olmasından ötürü geliştirilen bu sistemlerin eğitimdeki etkileri incelenmiştir.

Page ve diğerleri (2020) çalışmalarında Avustralya'da bulunan ve kronik hastalıkları nedeniyle okula devam edemeyen öğrencilerin eğitiminde yer alan telepresence robotların kullanımı ve tematik analizi incelenmiştir.

Weibel ve diğerleri (2020) çalışmalarında telepresence robotların kanser hastası olan çocukların ve ergenlerin sosyal ve akademik alanda okullarıyla bağlantıda kalmalarına yönelik yardımları incelenmiştir. Bu robot yapıları sayesinde kanser hastası öğrencilerin 
uzaktan öğrenim aksaklıklarının giderilmesi ve sınıf içi etkinliklerine aktif katılımları üzerine çalışma yapılmıştır.

Jakonen ve diğerleri (2021) çalışmalarında video konferansların yaygınlaşmasıyla birlikte uzaktan eğitimlerde yer almaya başlayan telepresence robotlar ele alınmıştır. Telepresence robotların video konferanslardan farklı olarak haraketliliğe ve kamera kontrolüne olanak sağlanmasının ve uzaktan eğitim görmekte olan öğrencilerin sınıf etkinlikleri sırasında dikkati insanlar, nesneler ve çevresel yapılar arasında kaydırmak için sağladığı olanaklar incelenmiştir.

Matsuda ve diğerleri (2021) çalışmalarında insan ilişkilerinde önemli bir sorun oluşturan sadece dinlemeye yönelik yürütülen telefon görüşmelerinin geliştirilmesi üzerine bir inceleme gerçekleştirilmiştir. Bu çalışmada ScalableBody adı verilen bir telepresence robotlar ile insanların sadece yüzlerini değil aynı zamanda yüksekliğini değiştirmesini sağlayan dikey bir aktüatöre ve kullanıcılara geniş bir görüş açısı sağlayan çok yönlü bir iletişimin sağlanmasına yardımcı olduğu tespit edilmiş ve bu robotların etkili iletişimdeki önemi sunulmuştur.

Zoder ve diğerleri (2021) çalışmalarında telepresence robotların okullarda tele danışmayı desteklemek için kullanılması ele alınmıştır. Bu robotların uzaktan bir konumda hareketlilik ile anında video konferans sağlama yeteneği nedeniyle diğer teknolojilere göre tercih edilebilir olmasından ötürü otizm spektrum bozukluğuna sahip öğrencilerin eğitimlerinde kullanılması talepleri incelenmiştir.

\section{TELEPRESENCE ROBOTLARIN KULLANIM ALANLARI}

Telepresence robotlar profesyonel anlamda birden fazla alanda kullanılabilir. Literatür incelenerek kullanım alanları genel olarak bazı başlıklar altında toplanarak aşağıda verilmiştir.

\subsection{Sağlık Sektörü}

Dünya Sağlık Örgütü (WHO) verilerine göre 2000- 2050 yılları arasında dünya yaşlı nüfusunda \%22 oranlı bir artış olacağı belirlenmiş, bu artışla beraber yaşlı bakım süreçlerinde değişimler olacağ 1 ön görülmüştür. Bu değişimlerle teknolojik gelişimler bu süreçlere adapte edilmeye başlanmıştır. Yaşlı bakım süreçlerinde yeni trendlerden birisi de robotik sistemlerin yaşlı bakımına uyarlanması olmuştur. Evde hizmet uygulamalarında son dönemlerde telepresence robotlar ön plana çıkmıştır. Yetersiz sağlık hizmetleri ve personel sayısı göz önüne alındığında görülen talep artışı tahmin edilebilir bir seyirdedir. İlgili bireylerin bakım süreçlerinde; günlük yaşama yardım, destek ve tıbbi verilerin sağlanması konusunda proaktif bir telepresence robot kullanımı büyük oranda yardımcı olabilir (Koceski ve Koceska, 2016: 120-121).

Son y1llarda beyin işleyişinin bilgisayar ya da ara yüzlerle sinyal olarak robotik sistemlere aktarımı kaba ve ince motor kullanımlarından yoksun bireylerin hayatlarını kolaylaştırma konusunda büyük bir adım olmuştur. Genel olarak nöroseptik protezlerle desteklenebilen telepresence robotlar engelli bireylerin günlük hayatlarını devam ettirme konusunda daha kaliteli bir süreç sunabilir. Kullanıcılar haricen bir işaret ve/veya gereç kullanmadan beyin sinyallerini kullanarak bir telepresence robotu harekete geçirebilir ve hareket süreçlerini 
kontrol edebilir. Bu sistem engelli bireylerin toplumsal iletişiminde de büyük bir rol oynamaktadır (Leeb vd., 2015: 696-697).

Zaman veya personel kısıtına bağlı gözlemlenemeyen hastalar ya da vefat durumlarda hata payı ve yetersizliğe bir çözüm olarak sağlık alanında kullanılmak üzere üretilen telepresence robotlar bir tıbbi asistan olarak hizmet verebilir. Geliştirilen yazılımlar ve donanımlarla telepresence robotuna eklenen steteskop ve ultrason portları ile doktor müdahalelerinin hızlıca yapılabildiği teşhis / tanı süreçlerinin daha sağlıklı yürütüldüğü bu robotlar bir Windows / Android işletim sistemi ile kolayca test edilebilir bu da daha pratik bir tıbbi konsültasyon imkânı sunar (Carranza, 2018: 1).

Yerel internet bağlantısı çerçevesinde mobil kontrol ya da otonom olarak hizmet verebilen telepresence robotlar hastaların ev içerisinde rutin bakımları için bir seçenek olarak görülebilir. Kişilerin kullanması gereken ilaçları saat bazlı hatırlatma, hasta kişilerin taşınması / fiziksel hareketlerine yardımcı olma, hasta ve doktor arasında uzaktan bağlantı kurabilme, tıbbi verileri depolayarak bir veri seti haline getirerek hasta seyir grafiği oluşturma süreçlerinde yardımcı olabilir (Hai vd,. 2019: 506).

\subsection{Kolluk Kuvvetler}

Kimyasal ya da biyolojik bir saldırı esnasında askeri uçak sortilerinde ya da bakım biriminde görev yapabilecek telepresence robotlar operasyonlar sürecinde tehlikeli irtifa hatları, zehirli gaz salınımı süreçlerinde ilgili donamım desteği ile yönlendirilebilir. Robotların dokunma, görme ya da işitsel duyu becerileri sunan arayüzleri ve VR ile joystickler sayesinde teknik bakım ekibi insansız uçakların tehlikeli bölgelerde uzak üs ya da istasyonlardan bakımlarını denetleyebilecektir. Bu yönleriyle telepresence robotlar hem pilotajlık hem de bakım kısmında ordular için karmaşık olan sistemlerin çözümlenmesi, incelenmesi ve denetlenebilmesi için bir araç olabilecektir (Julian ve anderson, 1988).

Operasyonlar ya da savaş esnasında yaralı kolluk kuvvet personellerinin bulunduğu yerlerin tespit edilebilmesi ve o bölgeden kurtarılması geleneksel sistemlerde diğer personellerin bölge keşif ve müdahalesi ile yapılmaktadır. Uzaktan kontrol edilebilirken bazı aparat destekleri ile bu bölgelerin keşif sorumluluğu robotlara devredilebilir. Askeri kurtarma robotları yalnızca savaş ve operasyonlarda değil ulusal güvenliği tehdit eden doğal afet, zehirli gaz salınımları, biyolojik saldırılar ve salgın süreçlerinde de hem personel tarafından hem de ordu personelleri aracılığıyla afetzedelere ulaşımlarda kullanılabilir (Choi, 2019: 665).

Askeri süreçlerde personellerin yaralanmaları doktorların günlük yaşamda gördüğü vakalardan farklılık gösterir, askerin yerinin ivedilikle tespiti yaralanma çeşidi ve yaralanma derecesinin hızlıca tespit edilip sağılık personeline iletilmesinde askeri tıp amaçlı üretilen telepresence robotların kullanımı mümkün olabilmektedir (Satava, 1997: 118).

Farklı birkaç donanım yardımı ile ordu bünyesinde bulunan robotlar; kullanıcının kontrolü ile engebeli alanlarda, afet durumlarında, zehirli gaz ve metallerin tespit edilmesinde kullanılabilir. Bununla beraber robot bünyesinde bulunan donanımlar robot menzilinde oluşabilecek tehditler önlenebilir yapay zekâ destekli yazılımlarla tehlikeler robot tarafından belirlenip imha edilebilir. Yine bu teknoloji ile birlikte robotların anlık görüntü ve ses iletimi ile de fizibilite ve keşif çalışmaları yapılabilir (Sharma, 2019: 27). 
Uzay incelemeleri, nükleer araştırmalar, toksik kimyasallardan arındırım, denizaltı keşifleri ya da biyolojik tehlikelere karşın kullanımlarda can kaybı veya yaralanmaların önlenmesi, insanların duygusal yaklaşımlarının minimize edilmesi, işitsel ve görsel geri bildirimler ile hatanın minimuma indirilmesinin hedeflendiği süreçlerde kullanılabilen telepresence robotlar ulusal güvenlik süreçlerinde yardımcı bir etken olabilir (Caldwell vd., 1996: 30).

\subsection{Eğitim Sektörü}

Hayatımızda yer edinen her alan gibi eğitim de inovatif değişimler göstermiş bu süreçte farklı eğitim metotları, öğrenim süreçleri, yardımcı araçlar ve teknik denemeler yapılmıştır. Eğitimde var olan eksiklikler ya da hataların onarımı için birden fazla yöntem denenmiş yine bu süreçte teknolojik gelişimler göz ardı edilmemiştir, gelişmeler devam ederken eğitimde robotların da kullanılması fikri ortaya atılmıştır. Eğitsel robotların yeni öğrenme süreçlerindeki kazandırdıkları deneyimlerle öğrenim davranışların modellenmesi gibi kavramlar oluşmuştur (Temizkan, 2014).

Günümüz eğitim teknolojilerinin önemli bir faktörü olan eğitsel robotlar işlevleri, maliyetleri ve modelleri bakımından birden fazla alternatife sahiptir. Bu gelişmeler kapsamında şu an için eğitimde kullanılan robotlar için ulaşılabilen en üst seviyelerde birisi de mimik yeteneği, sesli iletişim becerisi ve sosyal etkileşim yönü olan insansı robotlardır. Bu robot türleri ilgili yazılım ve donanım ile desteklenen programlamalar farklı öğrenim tekniklerinin sunulması, davranış ve öğrenim becerilerinin kaydedilerek kategorize edilmesi, ilgili gruplara doğru eğitim metodunun uygulanması adımlarının incelenmesi ile özellikle dil, müzik ve matematik derslerinin öğreniminde kullanılabilir (Mubin vd, 2013: 5).

Eğitim teknolojisinde yaşanan inovasyon temelli değişimler robot kullanımlarının da değişimini beraberinde getirmiş ve farklı alternatifleri de sunmaya başlamıştır. Bir sınıf ortamına farklı bir lokasyon üzerinden sanal olarak katılabilen bir eğitmenin aynı anda sınıf ortamında gezinebilmesi ve yüz yüze eğitim sistemine en yakın uygulamalardan biri olabilmesi yönüyle telepresence robotlar bazı eğitimsel uygulamalarda kullanılmaya başlanmıştır. Yapılan çalışmaya katılan öğretmenler bu uygulamayla ilgili olumlu bildirimlerde bulunarak hareketlerini kontrol edebildikleri robotların aktif iletişimde olumlu rol oynadığını belirtmiştir (Kwon, vd. 2021: 34).

Telepresence robotların sınıf ortamına uyarlanması eğitim sürecindeki aksama ve öğrenim modellemeleri için olumlu olacaktır. Herhangi bir engel kaynaklı sınıf ortamında bulunamayan öğrencilerin bu sistem aracıllğıyla sınıfta bulunabilme avantajıyla beraber yine birbirinden çok uzakta olan öğrenci grupları bu robotlar sayesinde birlikte öğrenim görebileceklerdir (Tanaka, vd. 2013: 5897).

Yine telepresence robotlar yaş engeli sebebiyle fiziksel olarak çok fazla efor sarf etmemesi gereken tecrübeli eğitmenlerin sınıf ortamında bulunabilmesine olanak sağlayarak eğitim sürecine olumlu katkı sağlayabilecektir (Okaruma ve Tanaka, 2021: 489).

Telepresence-eğitim hizmetleri birden fazla yönüyle eğitimde kullanılmaktadır fakat eğitim süreçlerine robotlarla beraber doğrudan entegre edilebilir, öğretmenlerin uzaktan kontrol sistemlerinde karşılaştı̆̆ 1 dezavantajları bu sayede azaltabilir ve öğrencilerin dikkatini daha fazla çekebilir. Kore' de geliştirilen ve eğitim için tasarlanan telepresence robot, öğrencilerin ilgisini çekebilecek bir tasarımla üretilmiş, 1 aylık eğitim süreçlerine dahil edilmiş ve bireysel 
öğrenme kıstasına oranla yüksek bir başarı elde edilmiştir. Robot $140 \mathrm{~cm}$ boyunda robot kontrol ve video kontrol sistemi olarak 2 bölümden oluşmuştur, robotun üst kisminda görüntüyü çift yönlü iletebilen bir monitör ve ses iletim donanımı alt kısmında ise tekerlekler, otomatik kontrol sistemleri, kablosuz bağlantı portları yer almaktadır. Öğretmenler; joystickler ve geliştirilmiş sistemler ile telepresence robotu sinıf ortaminda hareket ettirebilir. Deneyimler sonucunda öğretmenler robotun kullanılabilirliğinden büyük ölçüde memnun kalmış fakat dar görüş sistemi ve fiziki ortama yabancılıktan dolayı kullanımda zorluk yaşanabildiğini belirtmişlerdir. İlgili telepresence robot tasarımı aşağıda gösterilmiştir (Kwon vd., 2010: 154).

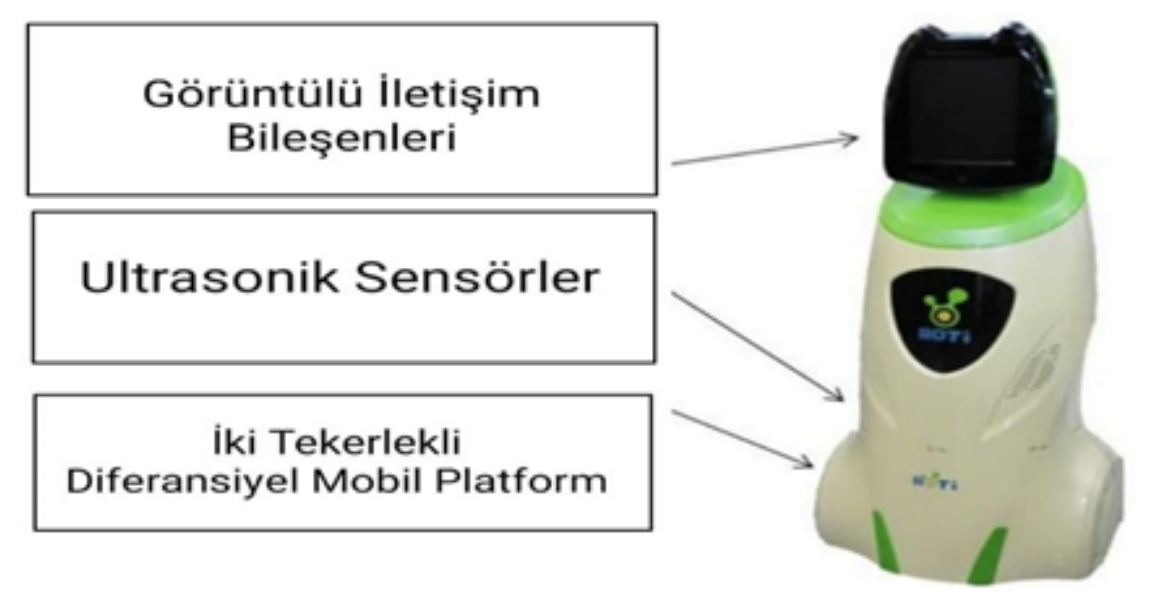

Kaynakça: (Kwon vd., 2010: 154).

\subsection{Hizmet Sektörü}

Endüstriyel anlamda kullanılan robotlar gelişen teknolojilerle hizmet alanlarına doğru yönelmeye de başlamıştır. Hizmet robotlarının bir türü olan telepresence robotlar genel olarak hareket kabiliyetleri ile öne çıkmaktadır, gövdelerinde yer alan kamera, mikrofon, görüntü ve ses iletme ile hareket sensörlerine ek bazı aparat, yazılım ve cihazlarla desteklenerek binaların güvenlik sistemlerinde de kullanılmaya başlanmıştır. Örneğin; duman sensörü ve sıcaklık sensörleriyle desteklenen bu robotlar olası bir tehlike anında komutlarla harekete geçerek müdahale edebilme ya da müdahale edebilecek birimlerle iletişime geçme imkânı sunabilir (Kuo vd., 2006: 4486).

Son yıllarda çeşitli alanlarda kullanılması için çok sayıda robot teknolojileri geliştirilmeye başlanmış, telepresence robotların da günlük yaşama entegrasyonu ile ev yaşamında kullanımı başlamıştır, kablosuz verici araçlarıyla internet bağlantısına sinyal gönderen, video kamera ve mikrofon desteğine sahip robotlar web tabanlı tele-operasyon arayüzler ya da mobil aplikasyonlar ile verilen komutlarla yönlendirilebilmektedir. Sensör tabanlı robotik sistemler, hafıza, görüntü işleme, görüntüyü anında iletebilme, navigasyon, genel ve özel çoklu görevlendirme komutları ile kapalı bina içerisinde oluşabilecek tehlikeleri anında denetlenebilmesine olanak sağlamış yine bununla beraber akıllı ev planlamalarına uyumlanarak bina içerisinde bulunan cihazlara ulaşımda da bir araç olmuştur (Schultz, 1991: 1065). 
Robotik sistemlerin yaygın olarak kullanılmaya başlandı̆̆ı alanlardan birisi de güvenlik sektörüdür. Yangın, hırsızlık ya da elektrik aksam problemleri gibi süreçlerde kapalı bina içerisinde sürekli devriye halinde olabilen telepresence robotlar, gövdelerinde bulundurdukları kameralar ve görüntü iletme sistemleriyle sürekli kontrol süreçlerine imkân verebilirken aynı zamanda uzaktan mobil uygulamalar ile kontrol edilebilmesi sayesinde bu gibi olumsuz durumlara hızlıca müdahale edilebilmesine olanak sağlayabilir (Trovato vd., 2017: 232).

Mobil aplikasyonlarla entegre edilen robotlar geliştirilen yazılımlarla desteklenerek farklı alanlarda da kullanılmaya başlanmıştır. Bina içerisinde CDMA ağı kullanılarak tasarlanan bir telepresence robot kullanıcısı için zaman ve konum farkı gözetmeksizin çalıştırılarak bina içerisinde komutlarla kullanılmaya başlanmıştır. İnsani duyu organlarını taklit edebilen bu robotlar sayesinde farklı konumda olan bir kullanıcı bina içerisinde fiziksel varlığı olmadan gezinebilir, bina içi giriş çıkışları kontrol edebilir ve kamera kayıt sistemleri ile bu süreçleri sonrasında tekrar izleyebilmiştir. Yine aynı robotlar aracıllğıyla iletişim kurabilen kullanıcılar farklı konumda bulunmalarına rağmen robotlar aracılığılyla iletişimlerini sürdürmeye devam etmiştir. Bu çalışmalar sonucunda güvelik robotlarının bina korumalarında kullanılabilirliği test edilebilmiştir. (Ryu vd., 2006: 1091-1093).

\section{BİR SERVIS ROBOTU OLARAK TELEPRESENCE ROBOTLAR}

Terimsel olarak ilk kez 1948 yılında yayımlanan Waldo isimli yazında kullanılmıştır. Bu eserden etkilenen ABD'li bilim insanı Marvin Minsky bu yazından yola çıkarak, telepresence terimini kullandığı makalesini yayınlamış, bu makalede telepresence kavramı "Kişinin kendisini farklı bir alanda hissedebileceği bir ışınlama konsepti" olarak ifade edilmiştir (IJsselsteijn, 2005:7).

Türkçe'de bu kavram "uzabulum”, "uzabulunum" ya da "telebulunuş" kavramları ile ifade edilebilmektedir. Kelime anlamı olarak kişinin mevcut konumunu fiziki olarak değiştirmeden farklı bir lokasyonda bulunabilmesine imkân veren sanal uygulamalar olarak ifade edilebilir. Telepresence robotlar yine kişinin mevcut durumunu değiştirmeden farklı lokasyonlarda fiziksel etki bırakmasına yardımcı olabilen robotlar olarak tanımlanabilir (Aymaz vd,. 2016: 181).

Bir başka tanıma göre telepresence robotlar genel olarak hareket sensörü olan ve kullanıcının yönetebildiği tekerlek vb. hareket sistemi donanımı ile hareket ettirilebilen ve bir bilgisayara bağlı kamera sistemi ile görüntüleri çift yönlü iletebilen bir işletim sistemine sahip olan iki farklı bölümlerden oluşmuş hizmet robotlarıdır (Tonin vd., 2011: 4228).

1993'te ise Telesuit isimli oteller zinciri, müşterilerinin olası kriz durumlarda işlerini uzaktan yürüterek tatil süreçlerini en az zaman kaybı ile geçirmelerine olanak sağlamak amacıyla kullanmış ve bu da telepresence kavramının ticari amaçla ilk kullanımı olmuştur (https://thinktech.stm.com.tr/uploads/docs/1608824477_stm-blog-telepresence.pdf).

\subsection{Telepresence Robotların Çalışma Prensibi}

Telepresence robotlar en basit halleriyle 2 basamaktan oluşur. Birinci kısım teleoperasyon olarak adlandırılan uzaktan kumanda sistemidir. Kullanıcılar robotu uzaktan yönlendirerek fiziken olmadıkları bir konumda gerekli eylemleri gerçekleştirerek iletişime geçebilirler. İkinci kısım da robotun gövdesi olan donanım kısmıdır. Bu, bir anabilgisayar ve bu 
bilgisayara bağlı bir yazılım sistemi ile çevre algısının kullanıcıya iletildiği manipülatör sistemidir (Rangel vd., 2015: 3-4).

Elektroensefalogram yöntemi kullanılarak oluşturulmuş aparatlarla kullanıcı kişinin beyin dalgaları hareketli stant gövde üzerine konumlandırılmış bilgisayar ekranı olan robota yönlendirilir. Yorum yeteneğine sahip bu robotlar kişiden aldığı sinyallere bağlı olarak hareket başlatır; kızılötesi sensörleri ile yön kavramı özelinde hareket edebilen robotun bulunduğu alanda mevcut olan engelleri algılayabilmesi, belirlenen hedef güzergahlarında değişiklik yapabilmesi gibi işlevleri olan donanım ve yazılımlara sahiptir (https://www.elektrikport.com/).
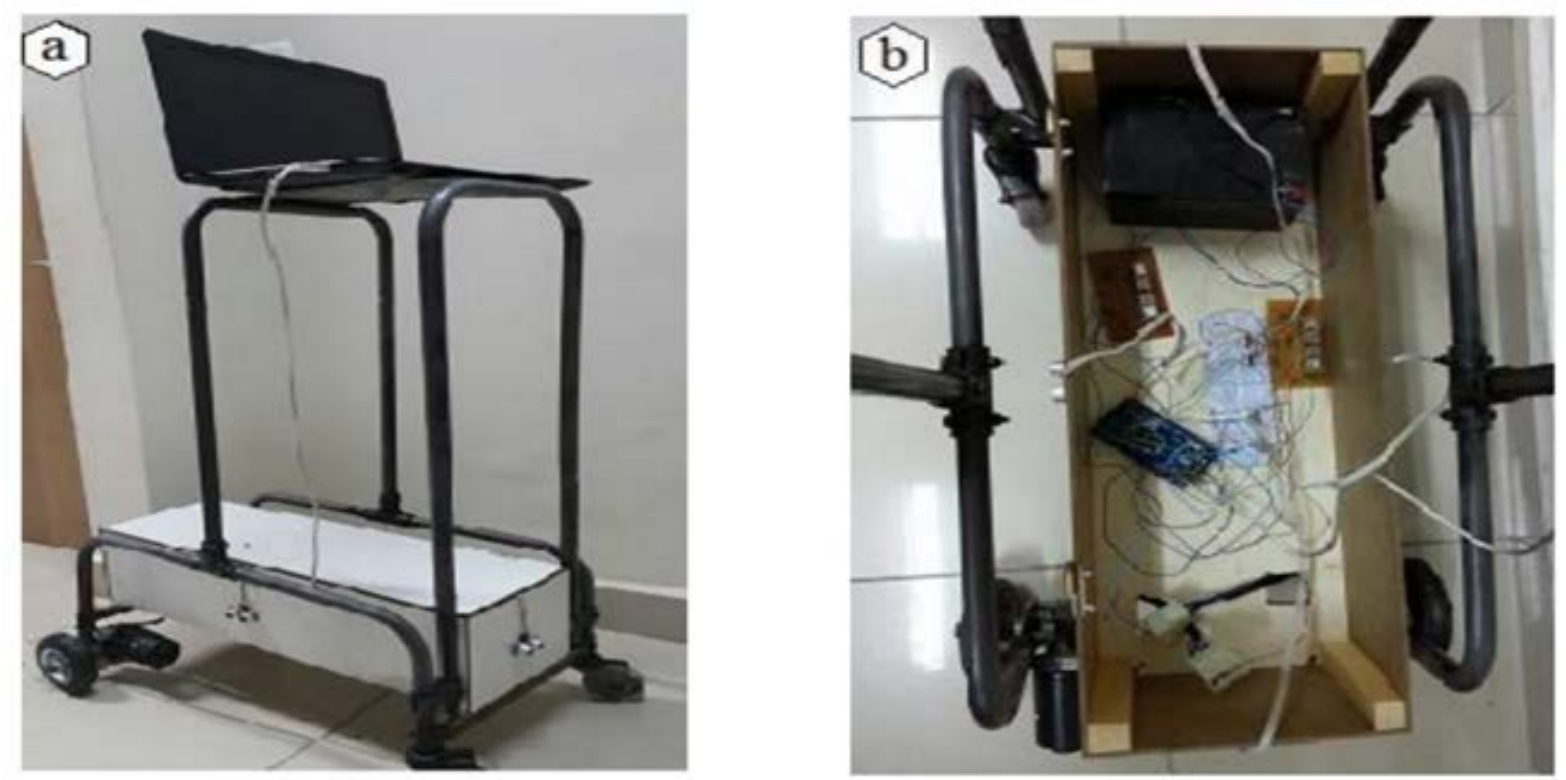

Kaynak: Aymaz, 2016

A fotoğrafında robotun genel görünümü paylaşılmıştır. Robot sisteminin üst kısminda bulunan bilgisayar sistemi merkezi işlem bölümüdür. Görüntünün iletimi, yapay zekâ tabanlı yazılımlar, haberleşme gereçleri ve kamera sistemi bu kısımda yer alır. Alt kısımda ise tekerlekler (denge ve motor kontrolleri için), motor sürücü devreleri ile çarpma ya da konumu yönetmek adına ultrasonik mesafe sensörü konumlandırılmış ve son olarak da kapalı hazne içerisinde geliştirme kartı, motor devre sistemleri, USB destek girişleri, elektronik devreler son olarak da akü yerleştirilmiştir. Tasarımın kapalı haznesinin iç kısmı ise b fotoğrafında gösterilmiştir (Aymaz, 2016).

Telepresence robotlarda; manipülatör üzerinde bulunan geliştirilmiş otomatik mesafe kontrol sistemlerinden iletilen veriler USB bağlantı sistemi ile anabilgisayara iletilir. Sensörler aracılığıyla bilgisayar robotun mesafeleri yönetebilmesine olanak sağlar (Çavdar ve Aymaz, 2015).

Uzak kullanıcının görüntüsü ekranda görüntülenir ve robot, etrafındaki herhangi bir şeyi görmek için hareket ettirilebilir. Bu robotların çoğu, internet bağlantısı olan herhangi bir yerden bir akıllı telefon veya bilgisayar ile kontrol edilebilir (https://ifr.org/news/improvinghealth).

\section{2. Örnek Vakalar}




\subsubsection{Motorika}

Uluslararası Robot Federasyonu tarafından yayımlanan verilerde VGo tarafından tasarlanmış ve Northside ISD tarafından desteklenen Rawlinson MS isimli robot lösemi tedavisi nedeniyle bağışıklık sistemi hassas olan ve izolasyon süreci sebebiyle sınıf ortamında bulunamayan 10 yaşındaki Mason Taylor'a okul süreçlerinde yardımcı olmaktadır. Bir telepresence servis robotu olan Rawlison MS aracılığıly M. Taylor bu süreçte arkadaşları ile iletişimini devam edebiliyor, derslere katılabiliyor, soru sorabiliyor ve okul içerisinde gezinebiliyor. Robot aparatları sayesinde söz hakkı isteyebiliyor ya da 1şığı açarak interaktif olarak ders süreçlerine katılabiliyor. M. Taylor'ın öğretmeni ve annesinin görüşü alındığında ise annesi kemoterapi süreçlerinde izolasyon kısıtlarında oluşan zararlarının biraz daha azaldığını ve iletişim kurabilmesinin Taylor için süreci biraz daha kolaylaştırdığını söylerken öğretmeni ise eğitim süreçlerinde Taylor'ın sınıf ortamında bulunabilmesinin öğrenim süreçlerindeki aksamayı telefi edilebilecek düzeylere indirgediği belirtiyor. Taylor ise bu süreçlerde robotu kontrol edebildiği ve eğitimine devam edebildiği için süreci daha motive bir şekilde ilerletebildiğini belirtiyor (https://ifr.org/news/improvinghealth).

\subsubsection{OAC}

Sürekli olarak üretken, uygun maliyetli ekip çalışmasını destekleyen yeni stratejiler ve teknolojiler arayışında olan şirket ilk defa bir ticaret fuarında telepresence sistemiyle karşılaşmıştır. Firma genel müdürü sistemin uzak ekip üyelerinin çok etkileşimli olmasına izin verirken seyahat süresi ve maliyetlerini azaltma potansiyeli karşısında çok şaşırmış ve 3 adet telepresence robot alarak ofislerine yerleştirmiştir. Şirkette Proje Müdür Yardımcısı olan Lindsey Avery, sistemin kullanım kolaylığı hakkında "Bir sürü ayarı değiştirmeye ya da bir sürü kablo ya da yazılım sistemiyle uğraşmaya gerek yok. Siz sadece uygulamayı indirin ve sürmeye başlayın." diyor ve ekliyor "Karşınızdaki kişinin yüzünü veya vücut dilini göremediğinizde, konuşmanın büyük bir kısmı kayboluyor. Müteahhitler, taşeronlar, mimarlar, planlamacılar, mühendisler, satıcılar ve müşterilerle bu muazzam toplantılar yapiyoruz."

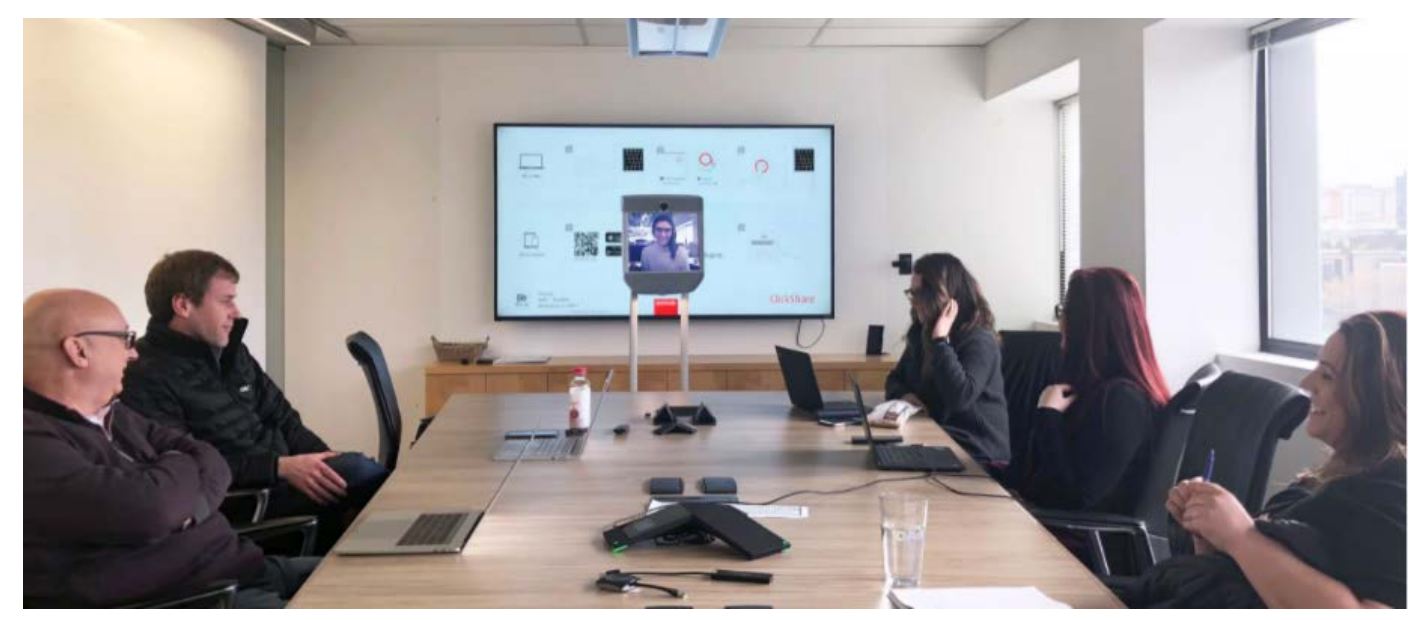

Kaynak: https://gobe.blue-ocean-robotics.com/casestudy-oac 
"Telepresence robotlar artık herkesin anlayabileceği standart bir teknoloji haline geldi. Neredeyse bizzat orada olmanın verdiği deneyim benzersiz." Peter Juhl Voldsgaard - GoBe Robots

\subsubsection{Microsoft}

Microsoft Research coğrafi olarak dağınık mühendislik ekipleri arasında günlük operasyonları optimize etme konusunda 2013 yılında presence robotları kullanmaya başlamıştır. Araştırmacı John Tang daha önce ayda bir Redmond'a seyahat ederken bu teknolojinin üç ayda bir seyahate izin verdiğini ve cihazın kendilerine bir ekip üyesi arama veya toplantıdan sonra bir tartışmaya devam etme özgürlüğü verdiğini belirtmiştir.

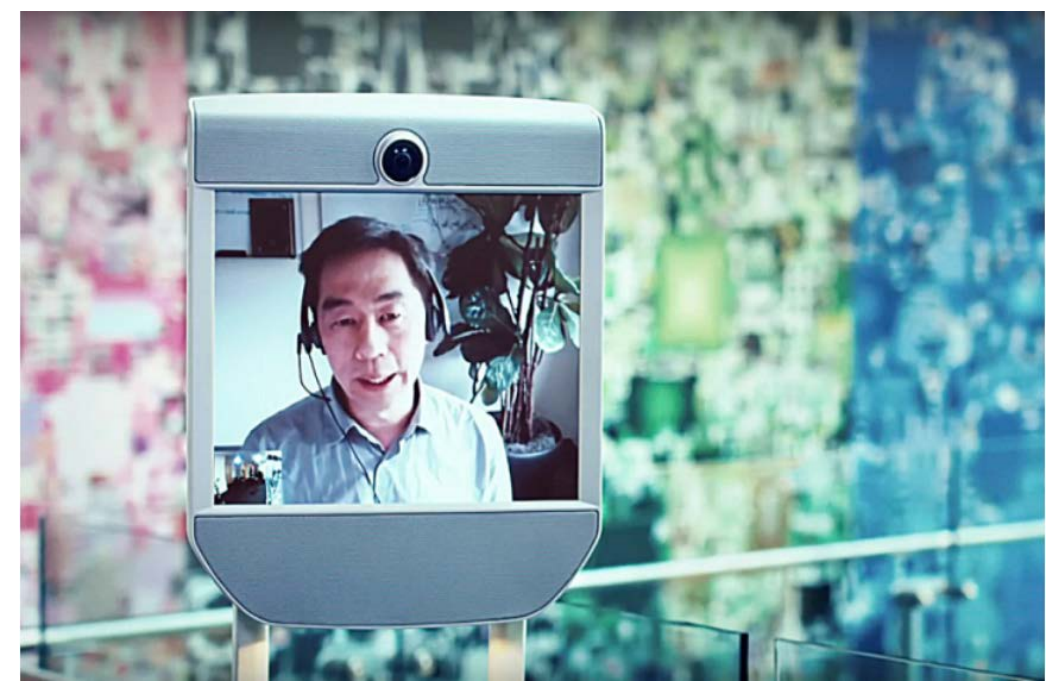

Kaynak: https://gobe.blue-ocean-robotics.com/

“Telepresence robotu kullanmak, fiziksel olarak sık sık seyahat etmeden ekibimle bağlantıda kalmamı sağladı." John Tang - Microsoft

\subsubsection{Michigan Eyalet Üniversitesi}

Michigan Eyalet Üniversitesi Uzaktan ve hibrit öğrenciler için daha fazla dostluk ve gelişmiş öğrenme fırsatlarını desteklemek için telepresence teknolojisinin kullanımında yüksek öğretimin öncüsüdür. Eğitim Fakültesindeki bazı programlarda öğretim üyeleri ve öğrenciler insan-robot etkileşimleri üzerine yaptıkları araştırmalar sonucunda kampüs içi programlarla kampüs dışındaki öğrencilere sınıf içi öğrenme deneyimi veren hibrit bir modele geçişi desteklemek için önce geleneksel video konferans yöntemini deneyen okul bunun uzaktaki öğrencilere kampüste otantik bir varlık sağlamadığını ve sinıftaki öğrencilerin deneyimlerinden uzaklaştıklarını keşfetmişlerdir. Böylece geleneksel yöntemden bu yeni teknolojiye geçiş yapmışlardır.

Tasarım stüdyosu eğitmenleri ve öğrenciler, telepresence robotları programa dahil etmenin en derin etkilerinden birinin, kelimenin tam anlamıla hibrit ve uzak öğrencilere masada bir koltuk vermesi olduğunu belirtmiştir. Grup veya araştırma projeleri zamanı geldiğinde, uzaktan öğrenenlerin ekipleriyle fiziksel olarak odadaymış gibi etkili bir şekilde buluşmalarına imkân tanıdığını söylemişlerdir. 
“Tüm robotlar eşit olarak yaratılmamıştır. Sonuç olarak bu robotlar programımıza en uygun olanlar." John Bell - Professor of MSU

\section{SONUÇ VE DEĞERLENDİRME}

İçerisinde bulunduğumuz yüz yılda robotikleşme yeni bir devrimsel süreci beraberinde getirmiş, ürün/hizmet üreticilerinin de dönüşüm süreçlerini büyük ölçüde etkilemiştir. İş yükü süreçlerinin önemli bir oranda insan faktöründen alınarak, uyuma, dinlenme, duygusal hatalara yer vermeme yetilerine sahip robotlara devredilmesi endüstri 4.0 ile ivme kazanmış, yapay zekâ makine öğrenme ve nesnelerin interneti ile desteklenen robotlar günlük hayatın içerisinde de yer almaya başlamıştır.

Teknolojik gelişimlerin hızına uyum sağlayan toplumlarda beklentiler teknolojiye aşinalık çerçevesinde değişmiş ve üreticilere yönelik talepleri bu çerçevede değişkenlik göstermeye başlamıştır. Yapılan çalışmalar incelendiğinde bu amaçlara uygun üretilen hizmet robotlarından birisi olan telepresence robotların yaygınlaşmaya başladığ döngülerine uyarlanmaya çalışıldığı gözlemlenmiştir.

Telepresence robotlar aracılığıyla mesafe kısıtının en aza indirgenmesi hem seyahat bütçeleri ya da konum değişiminin meydana getirdiği maddi külfetlerin hafifletilmesi hem de karbondioksit ayak izinin azalması, olası bir virüs ya da mikrobik süreçlerde bulaşı zincirinin kırılabilmesi, çalışma ve ulaşım sürelerinin minimize edilmesi ile toplumsal yaşam düzeylerinin iyileştirilmesi sürecine yardımcı bir etkendir.

Dünya nüfusunda yaşanan demografik değişimleri içeren veriler incelendiğinde yaşlı birey sayısında yaşanan artış, yaşlı bakım süreçlerinde de iyileştirmelere yönelik çalışmaları meydana getirmiştir. $\mathrm{Bu}$ iyileştirmelerle beraber kullanılan telepresence robotlar kişilerin; aileleri, bakımı ile yükümlü kimseler, arkadaşlar ve doktorları ile olan iletişimini geliştirmiş, bireyin evde geçirdiği süreçlerin kalite standardını artırmıştır. Telepresence robotların bakım süreçlerine uyarlanması ile yaşam süreçlerinde ek aparatlar ve bazı özel durumları gerektiren engelli bireylerin bakımları da kolaylaşmıştır. Evde geçirilen sürenin daha uzun olduğu bu istisnai durumlarda bu kişilerin telepresence robotlar aracılığıyla müze ziyaretleri ya da konferanslara katılabilmeleri sosyalleşme süreçlerini de olumlu etkilemiştir.

Sağlık problemi yaşayan bireylerde zayıf bağışıklık, bulaşıcı hastalık ya da olası bir mikrop veya virüs yayılımı gibi izolasyon süreçlerinde; hasta bakımları, günlük klinik uygulamaları, uzaktan sağlık yönlendirmelerinde de kullanılabilen telepresence robotlar iyileşme sürecinde sağlık personellerine ve hastaların fiziksel eylemlerine yardımcı olduğu kadar izolasyonun sebep olduğu psikolojik süreçlere de destek olabilmektedir.

Eğitim sektöründe kullanımları incelendiğinde ise; hastalık, engel, zaman ya da mesafe kısıtlarının minimize edilmesi adına kullanılan telepresence robotlar; hastalık ya da engel halinde özelikle çocuklarda akranlardan geri kalma veya ev süreçlerinin psikolojik etkilerinde iyileştirici bir destek görevindeyken zaman ya da mesafe engellerinde ise okullar arası uygulanan ortak politikalar, öğrenmede eğitmen eksikliği, alanında uzman eğitimcilerden uzaktan ders alabilme gibi eksikliklerin giderilmesinde bir araç olarak kullanılabilir.

Telepresence robotların faaliyetleri incelendiğinde gözlemlenen önemli bir işlev de ulusal güvenliğin sağlanmasına yönelik faaliyetlerde sağladığı destektir. Yapılan çalışmalarda 
telepresence robotların ilgili alanlarda kullanımıyla beraber insan faktörünün minimize edilmesi hem kolluk kuvvetleri personellerinin korunması hem de robotun bazı aparatlarla zenginleştirilerek hata payının azaltılmasıyla güvenlik operasyonlarında başarı yüzdesini artırdı̆̆ 1 gözlemlenmiştir.

$\mathrm{Bu}$ çalışma ile de yabancı literatürdeki az sayıdaki ve yerli literatürdeki sadece birkaç çalışmada konu edilen telepresence (uzabulunum) robotların çalışma prensibine ve benzer çalışmalardan farklı olarak, derlenen kullanım alanlarına değinilerek literatüre katkı yapıldığı ve incelenen vaka çalışmaları sayesinde telepresence robotların farklı sektörlerde kullanımına yönelik yapılacak uygulamalı çalışmalara ışık tutacağı ve kavramın farkındalığının artacağı ümit edilmektedir.

\section{KAYNAKÇA}

Akbaba, A. İ. (2019). Endüstri 4.0 ve 3 Boyutlu Yazıcılar. Ankara: İmaj Yayınevi.

Aymaz, Ş. (2016). Bir Uzabulunum Robotun Tasarımı ve Gerçeklenmesi (Doktora Tezi, Karadeniz Teknik Üniversitesi).

Bahrin, M. A. K., Othman, M. F., Azli, N. H. N., \& Talib, M. F. (2016). Industry 4.0: A review on industrial automation and robotic. Jurnal Teknologi, 78(6-13).

Bevilacqua, R., Cesta, A., Cortellessa, G., Macchione, A., Orlandini, A., \& Tiberio, L. (2014). Telepresence robot at home: a long-term case study. In Ambient Assisted Living (pp. 73-85). Springer, Cham.

Caldwell, D. G., Wardle, A., Kocak, O., \& Goodwin, M. (1996). Telepresence feedback and input systems for a twin armed mobile robot. IEEE Robotics $\mathcal{E}$ Automation Magazine, 3(3), 29-38.

Carranza, K. A. R., Day, N. J. B., Lin, L. M. S., Ponce, A. R., Reyes, W. R. O., Abad, A. C., \& Baldovino, R. G. (2018, November). Akibot: A telepresence robot for medical teleconsultation. In 2018 IEEE 10th International Conference on Humanoid, Nanotechnology, Information Technology, Communication and Control, Environment and Management (HNICEM) (pp. 1-4). IEEE.

Cha, E., Chen, S., \& Mataric, M. J. (2017, August). Designing telepresence robots for K-12 education. In 2017 26th IEEE International Symposium on Robot and Human Interactive Communication (RO-MAN) (pp. 683-688). IEEE.

Choi, B., Lee, W., Park, G., Lee, Y., Min, J., \& Hong, S. (2019). Development and control of a military rescue robot for casualty extraction task. Journal of Field Robotics, 36(4), 656676.

Cortellessa, G., Fracasso, F., Sorrentino, A., Orlandini, A., Bernardi, G., Coraci, L., ... \& Cesta, A. (2018). ROBIN, a telepresence robot to support older users monitoring and social inclusion: development and evaluation. Telemedicine and e-Health, 24(2), 145-154.

Çavdar, T. ve Aymaz, Ş. "Bir Uzabulum Robotun Tasarımı ve Gerçeklenmesi”, Mühendislikte Yeji Teknolojiler Sempozyumu (MYT 2015), sayfa: 220-226, 22-24 Ekim 2015, Bayburt, Türkiye. 
Çavdar, T., Aymaz, Ş., ve Aymaz, S. "Uzabulunum Robotlarda Konum Tespiti", 2016 Otomatik Kontrol Ulusal Toplantısı (TOK'2016), sayfa: 181-184, 29 Eylül-01 Ekim 2016, Eskişehir, Türkiye.

Çengelci, B., ve Çimen, H. (2005). Endüstriyel Robotlar. Makine Teknolojileri Elektronik Dergisi, 2(2), 69-78.

Firat, S. Ü., ve Firat, O. Z. (2017). Dördüncü Sanayi Devriminde Riskler Robotlar Ve Yapay Zekanın Yönetişim Sorunları. Global Sanayici: Ekonomi ve İş Dünyası Dergisi, 8(81), 6670 .

Fischer, A. J., Bloomfield, B. S., Clark, R. R., Mcclelland, A. L., \& Erchul, W. P. (2019). Increasing Student Compliance With Teacher İnstructions Using Telepresence Robot Problem-Solving Teleconsultation. International Journal Of School \& Educational Psychology, 7(Sup1), 158-172.

Gao, Z., Wanyama, T., Singh, I., Gadhrri, A., \& Schmidt, R. (2020). From industry 4.0 to robotics 4.0-a conceptual framework for collaborative and intelligent robotic systems. Procedia Manufacturing, 46, 591-599.

Goel, R., \& Gupta, P. (2020). Robotics and industry 4.0. In A Roadmap to Industry 4.0: Smart Production, Sharp Business and Sustainable Development (pp. 157-169). Springer, Cham.

Gonzalez-Jimenez, J., Galindo, C., \& Gutierrez-Castaneda, C. (2013, June). Evaluation of a telepresence robot for the elderly: a spanish experience. In International WorkConference on the Interplay Between Natural and Artificial Computation (pp. 141-150). Springer, Berlin, Heidelberg.

Hai, N. D. X., Nam, L. H. T., \& Thinh, N. T. (2019, July). Remote healthcare for the elderly, patients by tele-presence robot. In 2019 International Conference on System Science and Engineering (ICSSE) (pp. 506-510). IEEE.

IJsselsteijn, W. A. (2005). History of telepresence. 3D Communication: Algorithms, concepts and real-time systems in human centred communication, John Wiley \& Sons: Chichester.

Jakonen, T., \& Jauni, H. (2021). Mediated Learning Materials: Visibility Checks İn Telepresence Robot Mediated Classroom İnteraction. Classroom Discourse, 12(1-2), 121-145.

Julian, R. G., \& Anderson, T. R. (1988). Robotic telepresence: Applications of human controlled robots in Air Force maintenance. SCS Multi-conference on Aerospace Simulation III, pp59-67, 1988.

Koceski, S., \& Koceska, N. (2016). Evaluation of an assistive telepresence robot for elderly healthcare. Journal of medical systems, 40(5), 121.

Kuo, C. H., Chen, C. C., Wang, W. C., Hung, Y. C., Lin, E. C., Lee, K. M., \& Lin, Y. M. (2006, October). Remote control based hybrid-structure robot design for home security applications. In 2006 IEEE/RSJ International Conference on Intelligent Robots and Systems (pp. 4484-4489). IEEE. 
Kwon, O. H., Koo, S. Y., Kim, Y. G., \& Kwon, D. S. (2010, October). Telepresence robot system for English tutoring. In 2010 ieee workshop on advanced robotics and its social impacts (pp. 152-155). IEEE.

Kwon, Y., Kim, D., Ceylan, D., \& Fuchs, H. (2021). Neural Human Performer: Learning Generalizable Radiance Fields for Human Performance Rendering. Advances in Neural Information Processing Systems, 34.

Leeb, R., Tonin, L., Rohm, M., Desideri, L., Carlson, T., \& Millan, J. D. R. (2015). Towards independence: a BCI telepresence robot for people with severe motor disabilities. Proceedings of the IEEE, 103(6), 969-982.

Matsuda, A., Miyaki, T., \& Rekimoto, J. (2017, March). ScalableBody: a telepresence robot that supports face position matching using a vertical actuator. In Proceedings of the 8th Augmented Human International Conference (pp. 1-9).

Mubin, O., Stevens, C.J., Shahid, S., Mahmud, A.A., \& Dong, J. J. (2013). A Review Of The Applicability Of Robots İn Education. Journal Of Technology İn Education And Learning, $1,1-7$.

Oh-Hun Kwon, Seong-Yong Koo, Young-Geun Kim \& Dong-Soo Kwon, "Telepresence Robot System For English Tutoring," 2010 IEEE Workshop On Advanced Robotics And Its Social Impacts, 2010, Pp. 152-155.

Okamura, E., \& Tanaka, F. (2016, March). A pilot study about remote teaching by elderly people to children over a two-way telepresence robot system. In 2016 11th ACM/IEEE International Conference on Human-Robot Interaction (HRI) (pp. 489-490). IEEE.

Page, A., Charteris, J., \& Berman, J. (2020). Telepresence Robot Use For Children With Chronic Illness İn Australian Schools: A Scoping Review And Thematic Analysis. International Journal Of Social Robotics, 1-13.

Rangel, R., Romero, L., \& Garcia, M. (2015, November). Paynal, a low cost telepresence robot. In 2015 IEEE International Autumn Meeting on Power, Electronics and Computing (ROPEC) (pp. 1-4). IEEE.

Richert, A., Shehadeh, M., Plumanns, L., Groß, K., Schuster, K., \& Jeschke, S. (2016, April). Educating engineers for industry 4.0: Virtual worlds and human-robot-teams: Empirical studies towards a new educational age. In 2016 IEEE Global Engineering Education Conference (EDUCON) (pp. 142-149). Ieee.

Ryu, J. G., Shim, H. M., Kil, S. K., Lee, E. H., Choi, H. H., \& Hong, S. H. (2006, February). Design and implementation of real-time security guard robot using CDMA networking. In 2006 8th International Conference Advanced Communication Technology (Vol. 3, pp. 6-pp). IEEE.

Satava, R. M. (1997). Virtual reality and telepresence for military medicine. Annals of the Academy of Medicine, Singapore, 26(1), 118-120.

Schultz, R. J., Nakajima, R., \& Nomura, J. (1991). Telepresence mobile robot for security applications. In Proceedings IECON'91: 1991 International Conference on Industrial Electronics, Control and Instrumentation (pp. 1063-1066). IEEE. 
Severinson-Eklundh, K., Green, A., \& Hüttenrauch, H. (2003). Social and collaborative aspects of interaction with a service robot. Robotics and Autonomous systems, 42(3-4), 223-234.

Sharma, A., Tyagi, S., Mittal, D., \& Pundir, S. (2019). Third Eye of Indian Army with Virtual Telepresence Robot. International Journal of Radio Frequency Design, 5(1), 27-34.

Stoll, B., Reig, S., He, L., Kaplan, I., Jung, M. F., \& Fussell, S. R. (2018, February). Wait, can you move the robot? examining telepresence robot use in collaborative teams. In Proceedings of the 2018 ACM/IEEE International Conference on Human-Robot Interaction (pp. 14-22).

Tan, Q., Denojean-Mairet, M., Wang, H., Zhang, X., Pivot, F. C., \& Treu, R. (2019). Toward A Telepresence Robot Empowered Smart Lab. Smart Learning Environments, 6(1), 1-19.

Tanaka, F., Takahashi, T., Matsuzoe, S., Tazawa, N., \& Morita, M. (2013, November). Childoperated telepresence robot: a field trial connecting classrooms between Australia and Japan. In 2013 IEEE/RSJ International Conference on Intelligent Robots and Systems (pp. 5896-5901). IEEE.

Temizkan, M. (2014). Eğitimde Yenilikçi Yaklaşımlar: Robot Uygulamaları, Yayımlanmamış Yüksek Lisans Tezi, Gazi Üniversitesi, Eğitim Bilimleri Enstitüsü, Ankara.

Tonin, L., Carlson, T., Leeb, R., \& Millán, J. D. R. (2011, August). Brain-controlled telepresence robot by motor-disabled people. In 2011 Annual International Conference of the IEEE Engineering in Medicine and Biology Society (pp. 4227-4230). IEEE.

Topkaya, Ö. (2016). Dünyada Endüstriyel Robot Sektörü Ve Çalışma Hayatına Etkileri. Ataturk University Journal Of Economics \& Administrative Sciences, 30(5).

Trovato, G., Lopez, A., Paredes, R., \& Cuellar, F. (2017, August). Security and guidance: Two roles for a humanoid robot in an interaction experiment. In 2017 26th IEEE International Symposium on Robot and Human Interactive Communication (RO-MAN) (pp. 230-235). IEEE.

Walker, G. R., \& Sheppard, P. J. (1997). Telepresence-the future of telephony. BT Technology Journal, 15(4), 11-18.

Weibel, M., Nielsen, M. K. F., Topperzer, M. K., Hammer, N. M., Møller, S. W., Schmiegelow, K., \& Bækgaard Larsen, H. (2020). Back To School With Telepresence Robot Technology: A Qualitative Pilot Study About How Telepresence Robots Help School-Aged Children And Adolescents With Cancer To Remain Socially And Academically Connected With Their School Classes During Treatment. Nursing Open, 7(4), 988-997.

Yang, L., \& Neustaedter, C. (2018). Our house: living long distance with a telepresence robot. Proceedings of the ACM on Human-Computer Interaction, 2(CSCW), 1-18.

Yang, L., Jones, B., Neustaedter, C., \& Singhal, S. (2018). Shopping over distance through a telepresence robot. Proceedings of the ACM on Human-Computer Interaction, 2(CSCW), $1-18$. 
Zoder-Martell, K. A., Floress, M. T., Schiuchetti, M. B., Markelz, A. M., \& Sayyeh, L. (2021). Teachers' Willingness To Use A Telepresence Robot For Consultation With Students With Autism Spectrum Disorder. Contemporary School Psychology, 1-15.

https://www.elektrikport.com/makale-detay/insan-beyin-dalgalarini-kullanabilentelepresence-robotlar/17045\#ad-image-0 (Erişim tarihi 29.09.2021)

https://thinktech.stm.com.tr/uploads/docs/1608824477_stm-blog-telepresence.pdf? (Erişim tarihi 29.09.2021)

https://mag.bilgi.edu.tr/tr/haber/robotlar-ile-uzaktan-varolus/ (Erişim tarihi 29.09.2021)

https://www.epfl.ch/en/ (Erişim tarihi 29.09.2021)

https://ifr.org/news/improving-health (Erişim tarihi: 15.10.2021) 